\title{
Soft hyaluronic gel promotes cell spreading, stress fibers, focal adhesion, membrane tension by phosphoinositide signaling, not traction force
}

\author{
Kalpana Mandal ${ }^{1,{ }^{*}}$, Dikla Raz-Ben Aroush ${ }^{1,2}$, Zachary Graber $^{3}$, Bin $\mathrm{Wu}^{4}$, Chan Young Park ${ }^{5}$, \\ Jeffery J. Fredberg ${ }^{5}$, Wei Guo ${ }^{4}$, Tobias Baumgart ${ }^{3}$, and Paul Janmey ${ }^{1,}{ }^{*}$ \\ ${ }^{1}$ Institute for Medicine and Engineering, University of Pennsylvania, Philadelphia, PA 19104 \\ ${ }^{2}$ Kennedy Institute of Rheumatology, University of Oxford, Oxford OX3 7FY, UK \\ ${ }^{3}$ Department of Chemistry, University of Pennsylvania, Philadelphia, PA 19104 \\ ${ }^{4}$ Department of Biology, University of Pennsylvania, Philadelphia, PA 19104 \\ ${ }^{5}$ School of Public Health, Harvard University, Boston, MA
}

\section{Abstract}

Cells respond to both their chemical environment and to microenvironmental stiffness by the process of mechanotransduction. The mechanisms by which cells monitor and respond to the mechanical properties of their environment are largely unknown. Cellular response to the stiffness of the substrate is highly cell type specific and depends on the chemical composition of the substrate and therefore the type of adhesion receptors that engage it. Nearly all studies of mechanobiology in vitro employ substrates coated with protein or peptide ligands for integrins, but the native extracellular matrix (ECM) is highly enriched with glycosaminoglycans and proteoglycans that can alter cell adhesion and signaling though integrins. Hyaluronic acid (HA) is one of the major ECM components that helps maintains the viscoelasticity of connective tissues, controls tissue hydration, and organizes the supramolecular assembly of proteoglycans. In this study we investigate the role of HA together with integrin ligands in promoting hepatocellular carcinoma cell (Huh7) spreading on very soft substrates (300 Pa), resulting in morphology and motility similar to that which these cells develop only on stiff substrates ( $30 \mathrm{kPa} /$ glass) in the absence of HA. In particular, we test the hypothesis that cell interaction with HA leads to activation of the PI3K/Akt signaling pathway, which in turn promotes actin remodeling to facilitate cell spreading without requiring high contractile forces that are generated on stiff substrates. Inhibition of polyphosphoinositide turnover whether by two different PI3kinase inhibitors or by a cell-permeant polyphosphoinositide-binding peptide causes both Huh7 cells and murine fibroblasts to decrease spreading and detach whereas cells on stiffer substrates show almost no response. Traction force microscopy (TFM) shows that the cell maintains a very low total strain energy and net contractile moment on HA substrates as compared to stiff $30 \mathrm{kPa}$ substrate even though cells on both substrates have large spread areas, extensive focal adhesions, and actin bundles (generally called stress fibers). Measurements of cell membrane tension by lipid tether pulling show a similar level of membrane tension on HA substrate as on stiff substrates.

"Corresponding author. 
These results suggest that simultaneous signaling stimulated by HA and an integrin ligand can generate PI3K-dependent signals to the cytoskeleton that mimic those generated by high cellular tension, to produce increased actin and focal adhesion assembly and large spread areas.

\section{Introduction:}

Many cell types alter their structure and function depending on the mechanical properties of the materials to which they adhere and on the type of adhesion receptor by which they bind [1]-[4]. In vivo, cells engage their extracellular matrix (ECM) both by mechanosensitive adhesion complexes and by other surface receptors for ECM components that cannot act as adhesive anchors, but that potentially modify the mechanical signals transduced at the cell/ECM interface. Cellular reaction to extracellular matrix (ECM) depends upon the specificity of the ligand binding [2], [5]. Previous studies found that cardiomyocytes grown on soft hyaluronic acid gels coated with fibronectin (HA-Fn) developed well-structured sarcomeres despite the very low elastic modulus of this material, suggesting that the role of the cardiac jelly in early stages of cardiogenesis is more than that of a passive coupling matrix between the myocardial-cardiomyocytes and endocardial-endothelial cell layers enveloping it [6],[7].

Hyaluronic acid (or hyaluronan (HA)), a non-sulfated glycosaminoglycan polysaccharide, is a major ECM component that plays an important role in development, wound healing, and cancer progression[8]-[10]. In normal tissue, HA amount is determined by the balance between HA synthesis and degradation. An over production of HA or upregulation of HA receptors facilitates cell migration, invasion of tumor cells or rapid tumor growth[11]. Breast cancer cells synthesize more HA than normal cells, and high HA production is correlated with poor patient survival in various types of cancer including prostate, breast and ovarian cancer [12], [13]. HA localizes at the leading edge of the tumor [14].

Cells on HA substrate of stiffness $300 \mathrm{~Pa}$ can spread as much as on very stiff substrate $(10 \mathrm{kPa})$ when both are coated with a ligand for integrins, usually either fibronectin or collagen I [15], [16]. Cell interaction with ECM-bound HA is mediated by CD44, CD168 (RHAMM), and other cell surface receptors. CD44 is overexpressed in many cancers and has been shown to promote angiogenesis from tumors[17], [18]. Cell interaction with ECMHA through these receptors regulates many cell signaling pathways including Rho-GTPase, transforming growth factor beta (TGF- $\beta$ ) and focal adhesion kinase mediated (FAK) pathways [19].

Prior studies show a large effect of HA on cell morphology, stiffness, and contractility on soft gels containing Fn, but the molecular mechanism by which HA in the matrix exerts this effect is unexplored. This study is designed to determine if signals downstream of phosphatidylinositol-4,5-bisphosphate $\left(\mathrm{PIP}_{2}\right)$ or phosphatidylinositol-3,4,5-trisphosphate $\left(\mathrm{PIP}_{3}\right)$ control the effect of HA by inhibiting phosphatidylinositol-3-kinase (PI3K) or sequestering PIP2. Previous work showed that a cell-permeant fluorescent peptide derivative based on the $\mathrm{PIP}_{2}$-binding site of gelsolin can reversibly destabilize the actin filament network of fibroblasts and other cell types bound to glass, but does not alter their spread area or detach them from the substrate [20]. Manipulation of enzymes involved in $\mathrm{PIP}_{2}$ 
production showed that increasing cellular $\mathrm{PIP}_{2}$ levels massively increases actin assembly and stress fiber formation, whereas increasing $\mathrm{PIP}_{2}$ degradation destabilizes actin assembly[21]-[24]. PIP 3 , which is the lipid product of PI3K, regulates cell migration, proliferation, and growth [25]. A prominent effector of $\mathrm{PIP}_{3}$ is the serine-threonine kinase Akt, which binds to the membrane via $\mathrm{PIP}_{3}$, facilitating its activation by phosphoinositidedependent kinase 1 (PDK1).

Here we investigate the role of $\mathrm{HA}$ in $\mathrm{PIP}_{2}$ and $\mathrm{PIP}_{3}$ mediated signaling in hepatocellular carcinoma cells and fibroblasts. We explore the cell-substrate interaction process in HAmediated adhesion as well as on stiff polyacrylamide (PAA) substrates by traction force microscopy and by measuring the plasma membrane tension, which depends on contributions from lipid bilayer surface tension, hydrostatic pressure across the membrane, and the interaction between the plasma membrane with the underlying actin-cytoskeleton mediated by contractility of the actomyosin cortex[23], [26]-[28]. The ratio of $\mathrm{PIP}_{2} / \mathrm{PIP}_{3}$ coordinates actomyosin contractility by limiting myosin recruitment during plasma membrane expansion in tissue morphogenesis, thus ensuring proper cell shape [29].

\section{Materials and Methods}

\section{Hydrogel preparation:}

PAA Hydrogels are prepared as described in the previous work [30]. Briefly, for stiff $30 \mathrm{kPa}$ substrates, $13.8 \%$ acrylamide and $0.35 \%$ bis-acrylamide (Bio-Rad), $0.375 \% 3$ aminopropylsilyl (Thermo Fisher Scientific) and $0.125 \%$ tetramethylethylenediamine (Milliporesigma) are mixed in water. To prepare $500 \mathrm{~Pa}$ substrates, acrylamide was reduced to $3.6 \%$ and replaced with water to the same protocol as $30 \mathrm{kPa}$ recipe. Solutions are left for 30 mins to $1 \mathrm{hr}$ for polymerization at room temperature (RT). Sulfo-SANPAH is used for gel surface activation to facilitate protein conjugation for 3-5 mins under UV illuminate. Gels are laminated with $(100 \mu \mathrm{g} / \mathrm{ml})$ rat tail collagen type I (Corning) or human plasma or fish fibronectin by incubating $1 \mathrm{hr}$ at RT.

Hyaluronic acid gels are prepared using a HyStem Hydrogel Kit (Glycosil, BioTime) that consists of thiol-modified hyaluronan (average $\mathrm{MW} \approx 250 \mathrm{kDa}$ ), thiol-reactive cross-linker poly (ethylene glycol) diacrylate (PEGDA) and ExtraLink ( $\mathrm{Mw}=3400 \mathrm{Da})$ as described previously [4]. The HyStem system was dissolved in distilled water with $0.8 \% \mathrm{wt} / \mathrm{vol}$ concentration and kept at $37{ }^{\circ} \mathrm{C}$ for $1 \mathrm{hr}$. Rat tail collagen I (Corning) or human plasma fibronectin was added to the solution at $100 \mu \mathrm{g} / \mathrm{ml}$. Extralink was prepared by dissolving in distilled water at $0.5 \% \mathrm{wt} / \mathrm{vol}$ concentration for $30 \mathrm{mins}$ at RT and added to the HA solution at 1:4 vol/vol concentration and left for 30 mins to polymerize at RT.

\section{Cell Culture, reagents, time-lapse imaging, and data analysis:}

Huh7 cells are a hepatocyte-derived carcinoma cell line taken from a liver tumor of a 57year-old Japanese male in 1982 (The line was established by Nakabayshi, H. and Sato, J) [31]. Huh7 cells were grown in 1X DMEM (Life Technologies) supplemented with 10\% (vol/vol) FBS (GE Healthcare Life Sciences) at $37{ }^{\circ} \mathrm{C}$ with $5 \%$ (vol/vol) $\mathrm{CO}_{2}$. Cells were plated at a density of 30,000 cells/gel for $22 \mathrm{~mm}$ diameter coverslip and left for $24 \mathrm{hrs}$ at 
$37{ }^{\circ} \mathrm{C}$ with $5 \%$ (vol/vol) $\mathrm{CO}_{2}$ before performing any experiments. Cells were taken for time lapse imaging $24 \mathrm{hrs}$ after seeding the cells on gel. Time lapse images were acquired with Leica DMIRE2 microscope using ivision software. An environmental chamber was used to maintain the temperature at $37{ }^{\circ} \mathrm{C}$ and $5 \% \mathrm{CO}_{2}$ for live cell imaging. Images were acquired at multiple positions every 5 minutes/ 1 minutes/10 minutes for 3-hours or more with $10 \mathrm{X}$

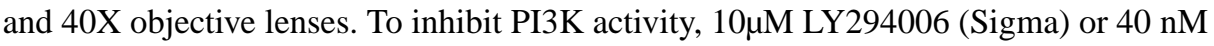
wortmannin was added to Huh7 cells after $1 \mathrm{hr}$ of control time lapse imaging. $10 \mu \mathrm{M}$ PBP10 or $300 \mathrm{nM}$ wortmannin was used for 3T3 cells. Control experiments were performed by adding an equivalent amount of DMSO, the solvent for PI3K inhibitors, to the medium.

ImageJ software was used to determine cell areas, and for quantitative analysis in motility assays. Matlab was used for traction force calculation. Cell area, dynamics, migration were calculated by using Fiji. Cell dynamics were determined by manually tracking the centroid of the cell in Fiji.

\section{Immunostaining, fluorescence imaging and western blot:}

Immunofluorescence experiments were performed as described previously [32]. Briefly, cells were fixed with $4 \%$ paraformaldehyde followed by 5\% BSA and $1 \%$ Saponin (Sigma) for blocking and permeabilization. Permeabilized cells were incubated with primary antibodies for $1 \mathrm{hr}$ (Alexa- Fluor 647 phalloidin (Invitrogen), and anti-vimentin (Novus Biologicals), anti-tubulin, DAPI (Sigma)). MCherry Grp1 a fluorescent protein that was purified in the lab, was used for $\mathrm{PIP}_{3}$ staining. The mCherry-PH domain (267-399) of human Grp1 was cloned into the pET16b vector (VectorBuilder, Santa Clara, CA, USA). The protein purification procedures were described previously with minor modification. Briefly, the mCherry-PH vector was transformed into E. coli BL21-(DE3) cells and protein expression was induced with $500 \mu \mathrm{M}$ isopropyl- $\beta$-d-thiogalactoside (IPTG) at $37{ }^{\circ} \mathrm{C}$ for 4 hours. The protein was purified with a His trap affinity column (GE, Piscataway, NJ) and was further purified with a Superdex 200 16/600 column. Immunofluorescence images were acquired with 40X and 100X magnification.

Western Blot: Huh7 cells were plated on $30 \mathrm{kPa}, 500 \mathrm{~Pa}$ - PAA gels and HA gels for $24 \mathrm{hrs}$. Then cells were lysed with lysis buffer $(10 \mathrm{mM}$ Tris-HCl, $\mathrm{PH} 7.4,150 \mathrm{mM} \mathrm{KCl}, 5 \mathrm{mM} \mathrm{MgCl} 2$, $0.5 \%$ Triton X-100, plus protease inhibitor and phosphatase inhibitor). The cell lysates were assayed for immunoblot using anti phospho-Akt (CST, 7291), and anti GAPDH (CST, 5174)

\section{Traction force Measurement:}

To perform TFM experiments, hydrogel substrates were prepared as described before [30], [33]. In addition, $1 \%$ of $200 \mathrm{~nm}$ fluorescently labeled green-beads ( $2 \%$ solid, Thermo Fischer Scientific) were added to both of the HA and PAA gel solution before leaving it for polymerization. After $24 \mathrm{hrs}$ of plating cells, cell and fluorescent bead images were acquired at multiple positions. After removing cells by adding trypsin, relaxed images of the beads were acquired at the same positions. For the TFM analysis, a custom-built Matlab code was used. A displacement field, total strain energy and net contractile moment of the cell were calculated. The details of the calculation can be found in [33], [34]. Briefly, a pair of stressed and relaxed images of the bead are used to determine the displacement field (via 
image cross-correlation. The cross-correlation window size was $32 \times 32$ pixels, and the window overlap was 28 pixels. From the displacement fields, we calculated cellular contractile forces per unit area using constrained Fourier Transform Traction Microscopy [33].

\section{Optical Tweezers set up and Experiment}

Optical trapping experiments were performed using a home-built optical trap on an Olympus IX70 epifluorescence microscope as described previously [5]. Trapping was performed using a $1064 \mathrm{~nm}$ continuous wave fiber optic laser (IPG Photonics, Oxford, MA) with an output power of $3 \mathrm{~W}$. This laser power is further adjusted in the laser pathway by the use of a half-wave plate and polarizing beam splitter, with the excess laser power shunted off to a beam dumpThe laser was focused onto the sample through a 60X 1.1 NA water immersion objective (Olympus) mounted in upright position on a motorized stage (MS-2000; Applied Scientific Instrumentation, Eugene, OR) to allow for finely controlled movement of the trapping focus. Fluorescence imaging was performed simultaneously with trapping using a second 60X 0.9 NA water immersion objective in an inverted position. Images were captured using an EM-CCD camera (Hamamatsu, Bridgewater, NJ).

For lipid tether pulling experiments, cells were plated on collagen-coated $300 \mathrm{~Pa} \mathrm{HA}$ and 30 kPa PAA gels in delta $\mathrm{T}$ dishes which allow for precise temperature control of the dish throughout the optical trapping experiments (Bioptechs, Butler, PA). All experiments were performed at $37^{\circ} \mathrm{C}$. Before the experiments, cells were incubated with hydrophobic DiI for approximately ten minutes to label the cell plasma membrane. The cell medium was then replaced with $\mathrm{CO}_{2}$ independent medium for the duration of the experiment. Tether pulling was performed using $6 \mu \mathrm{m}$ polystyrene beads. Beads were trapped in solution and then adhered to the membrane via nonspecific interaction between the membrane and the beads. After allowing a bead to adhere to the membrane for approximatel 3 one minute, the bead was pulled away in $2 \mu \mathrm{m}$ stepwise increments to form a thin lipid tether. After each tether extension step the trapping force peaks sharply before relaxing to the steady-state force, $F_{0}$, which is directly proportional to the membrane tension of the cell: $F_{0}=2 \pi \sqrt{2 \sigma \kappa}$, where $\sigma$ is the membrane tension and $x$ is the bending stiffness of the membrane.

Trapping force was measured by determining the displacement of the bead from the center of the trap. The displacement of the bead $(\Delta x)$ is related to the force of the trap $(F)$ via a simple Hookean spring relation: $F=k \Delta x$, where $k$ is the stiffness of the trap. Bead position was monitored by collecting backscattered light from the bead via the trapping objective and imaging with a CCD camera (XC-ST30; Sony, Park Ridge, NJ) linked with the motorized stage. The backscatter image was thereby fixed relative to the focal point of the trapping objective lens. A LabView code was used to fit the bead image in real time using a Gaussian ring function to determine the center position of the bead. To determine the trap stiffness, the drag-force method was used for calibration. Briefly, a motorized stage was used to drag a trapped bead through the solution at several fixed velocities. The force on the bead during the stage movement was determined by the drag force: $F_{\text {darg }}=6 \pi \eta r v$, where $\eta$ is the solution viscosity, $r$ is the radius of the bead, and $v$ is the velocity. The trap stiffness was 
then calculated based on the known drag force $F_{d r a g}$ and the measured displacement during the calibration.

\section{Results}

\section{A. Cell spreading on HA and $30 \mathrm{kPa}$ substrate:}

To study cell spreading and intracellular organization, Huh7 cells were cultured on $300 \mathrm{~Pa}$ HA- collagen, $300 \mathrm{~Pa}$ HA-FN, and $30 \mathrm{kPa}$ or $500 \mathrm{~Pa}$ collagen coated PAA substrates. Bright field images of the cell were taken after $24 \mathrm{hrs}$ of plating and cell areas were measured (Fig 1(a)). The result shows that the average cell area is significantly lower on $500 \mathrm{~Pa}$-PAA compared to $30 \mathrm{kPa}$ - PAA or $300 \mathrm{~Pa}$ HA substrates. There was no significant area difference between cells on $30 \mathrm{kPa}$ PAA collagen and $300 \mathrm{~Pa} \mathrm{HA}$ coated either with fibronectin or collagen (Fig 1(a)). This result confirms the previous finding that cells on soft HA substrates spread as much as they do on stiff substrates without HA [15]. One of the most striking features of cells grown on soft HA gels are actin bundles (Fig. 1) and prominent focal adhesions (Fig. 1(b)) that appear on substrates that are much too soft to support these structures if the substrate is 500 Pa PAA. Immunostaining images shows that the cells are able to form organized microtubule and vimentin networks on both of these two substrates but not on soft PAA substrates (Fig 1(b)).

\section{B. Effect of PI3K inhibition by Wortmannin and LY296004 in Huh7 cell}

Previous work showed that polyphosphoinositide (PPI) production is important for integrin signaling, actin assembly, and activation of FA proteins, and the loss of $\mathrm{PIP}_{2}$ can decouple integrin-mediated adhesion from force effects [35]-[37]. To determine more specifically which elements of PPI signaling are important for maintaining the spread cellular morphology on HA substrates, the PI3K inhibitors wortmannin and LY296004 were added after cells had adhered to the substrates. When Huh7 cells plated on soft HA or $30 \mathrm{kPa}$ PAA substrates are treated with the PI $3 \mathrm{~K}$ inhibitors, immediately after inhibition cells start to retract from the HA substrate, but cells on $30 \mathrm{kPa}$ PAA substrate show no effect (Fig 2 (a)). Within 15 mins of inhibition the cell area of Huh7 cells reaches a minimum followed by a slow recovery. Cells were observed over 2 to 3 hrs during which time cells return to their full spread area (Fig 2 (b)). Cell area at 15 mins calculated for HA and $30 \mathrm{kPa}$ PAA substrates shows a significant decrease (33\%) on HA substrate but no significant change on $30 \mathrm{kPa}$ PAA substrates. Control experiments with the carrier for both inhibitors, DMSO, show no change in cell area on both these substrates. Cell area change was observed over $3 \mathrm{hrs}$ (Fig 2 (c)).

To study the effect of PI3K inhibition on cell dynamics we tracked the centroid of the cell on these substrates. Cells are more dynamic on HA compared to PAA substrates (Fig 2 (d)). However, there was no significant effect on cell motility after a single treatment with wortmannin (Fig 2 (d)). We also used the LY296004 drug to inhibit PI3K in Huh7 cells, as shown in the bright field image. The cell area goes to a minimum within 15 mins after inhibition of PI3K by LY296004 as shown in (Fig 3(b)). After inhibition by LY296004, cells are less motile on both HA and $30 \mathrm{kPa}$ PAA. Moreover, cells are unable to spread back after treating with LY296004. 


\section{Effect of PIP $3 / \mathrm{PIP}_{\mathbf{2}}$ inhibition by wortmannin and PBP10 on 3T3 fibroblasts-}

To investigate further the hypothesis that chemical signaling from HA receptors rather than physical cues dominate PPI-mediated cell adhesion and stress fiber assembly, we performed similar experiments with normal 3T3 murine fibroblasts. 3T3 cells were treated with wortmannin or the cell-permeant PIP 2 -binding peptide PBP10 on HA-Fn gels and Fn-coated glass substrates Fig 4(a). As shown in Fig 4(b), when PBP10 is added to NIH 3 T3 fibroblasts plated on soft HA-Fn gels, the cells rapidly reduce their spread area and detach from the substrate in approximately 20 minutes, under conditions at which cells spread to the same extent on Fn-coated glass remain bound and maintain their spread area. When wortmannin is added, cells also retract from the HA-Fn substrate, but cells on Fn-coated glass maintain and even increase their area after recovery from wortmannin treatment (Fig 4(b)).

\section{C. $\mathrm{PIP}_{3} / \mathrm{AKT}$ signaling pathway activation}

The results of Figures 2-4 suggest that polyphosphoinositide production, in particular $\mathrm{PIP}_{3}$, is more important for maintaining the spread cell phenotype on soft HA-col or HA-Fn substrates than on stiff PAA substrates coated with these integrin ligands. We quantified the total amount of $\mathrm{PIP}_{3}$ on $300 \mathrm{~Pa} \mathrm{HA}$ and $30 \mathrm{kPa}$ PAA substrates using mCherry Grp1, a fluorescent protein that specifically binds $\mathrm{PIP}_{3}$ [38]. Fig 5(a) shows Huh7 cells stained with mCherry Grp1 on soft HA and stiff PAA substrates. Intensity distribution histograms on HA and PAA are shown in (Fig 5(b)). Intensities of each cell were normalized by the individual cell area. Average normalized intensity shows a significant increase (6 fold) of $\mathrm{PIP}_{3}$ level on $300 \mathrm{~Pa}$ HA-Col substrates compared to $30 \mathrm{kPa}$ PAA (Fig 5(b)) in Huh7 cells.

PI3K is recruited to the membrane and through PIP3 synthesis regulates many downstream effectors. $\mathrm{PIP}_{3}$ then recruits Akt at the membrane[39]. To check the activation of $\mathrm{PIP}_{3} / \mathrm{Akt}$ pathways, we performed western blot experiments on Huh7 cells grown on soft HA, stiff 30 kPa PAA, and soft 500Pa-PAA substrates. GAPDH was used as a non-specific measure of total cellular protein. The result shows an increase in p-Akt levels on $30 \mathrm{kPa}$ PAA and on HA substrates, whereas a low level of p-Akt was observed on 500 Pa PAA substrates (Fig 5(c)). This finding suggests a correlation between p-Akt levels and cell spreading, but not necessarily a linear dependence of p-Akt on $\mathrm{PIP}_{3}$ levels, since we observe higher $\mathrm{PIP}_{3}$ levels on HA substrates compared to 500Pa PAA substrate (Fig 5(a)).

\section{Cell traction force measurement by FTTM}

Traction forces exerted between cells and their environment are crucial for many biological functions including migration, wound healing, tissue organization and intracellular organization [30]. Cell traction forces (CTF) are generated by the actomyosin contractile machinery and depend on the cell-ECM interaction and the binding proteins involved in the process. To better understand ligand-specific cell substrate-interactions we have measured CTFs on both HA and PAA substrates. Fig 6(a) shows the cell generated displacement fields measured by beads embedded in the substrate. We have calculated the first order moment of the traction, which yields the contractile moment. Net contractile moment is determined by calculating the trace of the moment matrix, which measures the cell's strength of tending to dilate or contract the substrate (cite). The total energy transferred from the cell to the 
substrate is determined from the strain energy by integrating the traction over the whole cell area. Fig 6(b) and (c) show that both net contractile moment and the strain energy are significantly higher on the $30 \mathrm{kPa}$ PAA substrate than on $300 \mathrm{~Pa} \mathrm{HA}$. These results suggest that cell substrate interaction strength is higher and cells are much more contractile on the stiff substrate than on HA, even though their spread areas are similar.

To understand cell-ECM interaction better we have quantified focal adhesions (FA s) on these two substrates using immunostaining for paxillin, which is one of the major proteins recruited at FA complexes (Fig 6(d)). Paxillin images are intensity thresholded, and we have quantified the total FA area, the number of patches per $\mu \mathrm{m}^{2}$ area and the length of FAs (Fig 6(e)). Data are normalized by the individual cell area. These results show that the total number of patches and the total adhesion area per $\mu \mathrm{m}^{2}$ are higher on the HA substrate. However, the FA length is larger on the $30 \mathrm{kPa}$ substrate in correlation with higher traction force (Fig 6(f)).

\section{E. Cell membrane tension measurement by tether pulling}

Cell membrane tension is a critical regulator of cell spreading and motility, as well as exoand endocytosis, which require the extension of the plasma membrane and hence reorganization of actin [40]. We have performed tether pulling experiments to measure the membrane tension on soft HA and stiff PAA substrates (See materials and methods for details). Trapped beads are bound to the membrane to pull the tether Fig 7(a). The bead displacement from the center of the trap is tracked with time to calculate the force exerted on the bead by the membrane tether. The force depends on the surface tension of the membrane and the adhesive interactions between membrane constituents and the cytoskeleton (membrane adhesion energy). The optically trapped bead was moved away from the cell in a stepwise fashion to extend the lipid tether from the membrane (Fig. 7 (b), (c)). Each step of the bead triggers a peak in the force response as the tether is extruded from the membrane, which then relaxes to the $\mathrm{F}_{0}$ force value that indicates the cellular membrane tension. Forces measured on stiff PAA and soft HA substrates show a similar level of tension. However, a small increase is observed on the $30 \mathrm{kPa}-\mathrm{Col}$ substrate when compare to $300 \mathrm{~Pa} \mathrm{HA}-\mathrm{col}$ Fig $7(\mathrm{c})$.

\section{Discussion}

In previous works it has been demonstrated that cells on HA substrates which have stiffness in the range of 300-500 $\mathrm{Pa}$ are capable of spreading like a stiff substrate, but the mechanism by which cells compensate for the lack of mechanical activation activated by stiff substrates is not well understood [15]. Cell spreading, formation of stress fibers, and large FAs on HA gels cannot be explained by the same signals that mediate spreading on stiff surfaces due to low traction stress. This work demonstrates that a chemical stimulus dependent on HA can promote stress fiber assembly and cell spreading on very soft substrates. Loss of function mutations that diminish mechanosensing and response have been characterized, [6] [2], but gain of function mutations in which force- or stiffness- triggered responses can be elicited in the absence of the physical stimulus are thus far very rare [5], [41], but potentially very informative. In most cases upregulation of proteins that are engaged or activated during 
stiffness sensing and response is not sufficient for a cell to spread or stiffen on an abnormally soft matrix. For example, exogenous upregulation of alpha 5 integrin, the major receptor for fibronectin which is strongly upregulated as substrate stiffness increases, does not by itself cause cell spreading of soft surfaces even when they are saturated with fibronectin[42]. Therefore, alternate signals have been explored. PPIs, especially PI(4,5) $\mathrm{P}_{2}$ and $\mathrm{PIP}_{3}$, control numerous actin regulatory proteins including those that form FAs and promote actin assembly [43] (Janmey et. al in press ref 57). In the present work we propose a PI3K/Akt pathway activation mechanism by which cells can reproduce stiff substrate-like behavior on a soft $\mathrm{HA}$ based gel. Reducing $\mathrm{PIP}_{2} / \mathrm{PIP}_{3}$ levels leads to an immediate and large effect on cells adhered to soft HA based substrates but not on cells bound to stiff $30 \mathrm{kPa}$ substrate coated by the same integrin ligand. Cells recover from PI3K inhibition, suggesting a transient, partial inhibition of PI $3 \mathrm{~K}$ in the presence of wortmannin at this concentration. Use of higher concentrations of wortmannin or PBP10 in 3T3 cells can lead to total cell deadhesion. Our pull down experiment shows an upregulation of p-Akt on HA based substrates compared to PAA substrates having the same range of stiffness (300-500 Pa). However, the level of Akt activation is not directly linked to the overall $\mathrm{PIP}_{3}$ levels when compared with stiff substrates, which have lower overall $\mathrm{PIP}_{3}$, but equal Akt activation. This result suggests that $\mathrm{PIP}_{3}$ may play a role in activating the other downstream effectors and not only those involved in activating Akt ([39]).

Several studies suggest that adhesion and stress fiber assembly are regulated by mechanical stress at the integrin-mediated contact site[30], [44], [45]. Therefore, one hypothesis for increases in spreading, actin fiber formation and focal adhesion size in cells on soft HA substrates is that HA stimulates larger deformations of the cell-gel interface, so the cells impose a larger strain and ultimately generate the same stress as they do on stiffer PAA gels that promote similar spreading and cytoskeletal changes. Our results suggest that this hypothesis does not account for spreading on HA. Strain maps and traction forces measured on $300 \mathrm{~Pa} \mathrm{HA}$ and $30 \mathrm{kPa}$ substrates show a much larger net contractile moment and strain energy on the stiffer substrate, in spite of having the same cell spread as on HA. Focal adhesion quantification by paxillin staining confirms our TFM measurement. These data show that there are many small, possibly immature, focal adhesions formed on HA substrate whereas on $30 \mathrm{kPa}$, FAs are larger, which correlates with the higher strain energy reflecting stronger cell substrate interaction. Formation of immature FAs may increase cell dynamics on HA-based substrates. Membrane tension calculated by tether pulling experiment shows similar tension on both these substrates, and the magnitude of membrane tension at the ell's apical membrane does not correlate with the traction stress at the cell/substrate interface. The membrane tension may depend upon many factors such as membrane reservoirs, trafficking pathways or the exo-endocytosis process [46]-[49]. Our results suggest that cells may regulate membrane tension by localized PIP synthesis or membrane organization while maintaining adhesion dependent cell-substrate interaction revealed by TFM data.

Altogether, this work may modify the prevailing view that the stiffness of the microenvironment of the cell is a necessary and sufficient condition for the development of a specific cell phenotype. Integration of mechanical and biochemical signaling is essential to the response of cells in biological processes including embryological development and wound healing, as both the mechanical and biochemical features of the microenvironment 
change during maturation. Decreasing $\mathrm{PIP}_{2}$ levels or inhibiting $\mathrm{PIP}_{2}$ or $\mathrm{PIP}_{3}$ function reduce spreading and adhesion of cells to HA, but have little effect on cells bound to rigid substrates. This result is consistent with reports that several proteins involved in promoting actin polymerization such as N-WASP [50] and formins[51], [52] or focal adhesions such as talin[53], alpha-actinin, and vinculin[11], [54] are activated by either force or binding phosphoinositides [55]. Therefore both substrate stiffness and increase PIP2/PIP3 content might activate the same processes either independently or additively [BBRC ref] . In addition proteins involved in HA signaling, but not part of the integrin-based focal adhesion complexes, including ezrin and other ERM proteins, bind $\mathrm{PIP}_{2} / \mathrm{PIP}_{3}[56]$ and are released from the membrane when $\mathrm{PIP}_{2} / \mathrm{PIP}_{3}$ is inhibited. In summary, the present results implicate PPI signaling as an essential factor in formation of a spread cell phenotype characterized by actin assembly and focal adhesion formation, that is triggered by cell adhesion to substrates containing for HA and an integrin ligand even in the absence of mechanical stress that is required on substrates to which cells attach by integrins alone.

\section{Acknowledgements}

KM, ZG and BW were supported by Physical Science Oncology Center (PSOC) grant U54-CA193417. CYP and JJF were supported by a transnetwork project within CA193417. PAJ and DRBA thankfully acknowledge NIH grant GM111942. This work was also supported by the Center for Engineering Mechanobiology through NSF STC 1548571.

\section{References}

[1]. Byfield FJ, Wen Q, Levental I, Nordstrom K, Arratia PE, Miller RT, and Janmey PA, “Absence of Filamin A Prevents Cells from Responding to Stiffness Gradients on Gels Coated with Collagen but not Fibronectin,” Biophys. J , vol. 96, no. 12, pp. 5095-5102, Jun. 2009. [PubMed: 19527669]

[2]. Ganz A, Lambert M, Saez A, Silberzan P, Buguin A, Mège RM, and Ladoux B, "Traction forces exerted through N-cadherin contacts,” Biol. Cell , vol. 98, no. 12, pp. 721-730, Dec. 2006. [PubMed: 16895521]

[3]. Pelham RJ and 1 Wang Y, “Cell locomotion and focal adhesions are regulated by substrate flexibility.,” Proc. Natl. Acad. Sci. U. S. A, vol. 94, no. 25, pp. 13661-5, Dec. 1997. [PubMed: 9391082]

[4]. Mandal K, Balland M, and Bureau L, "Thermoresponsive Micropatterned Substrates for Single Cell Studies,” PLoS One , vol. 7, no. 5, p. e37548, 5 2012. [PubMed: 22701519]

[5]. Wang HB, Dembo M, and Wang YL, "Substrate flexibility regulates growth and apoptosis of normal but not transformed cells.,” Am. J. Physiol. Cell Physiol. , vol. 279, no. 5, pp. C1345-50, Nov. 2000. [PubMed: 11029281]

[6]. Chopra A, Lin V, McCollough A, Atzet S, Prestwich GD, Wechsler AS, Murray ME, Oake SA, Kresh JY, and Janmey PA, "Reprogramming cardiomyocyte mechanosensing by crosstalk between integrins and hyaluronic acid receptors.," J. Biomech, vol. 45, no. 5, pp. 824-31, Mar. 2012. [PubMed: 22196970]

[7]. Brutsaert DL, "Cardiac Endothelial-Myocardial Signaling: Its Role in Cardiac Growth, Contractile Performance, and Rhythmicity,” Physiol. Rev , vol. 83, no. 1, pp. 59-115, Jan. 2003. [PubMed: 12506127]

[8]. Rape AD, Zibinsky M, Murthy N, and Kumar S, "A synthetic hydrogel for the high-throughput study of cell-ECM interactions," Nat. Commun , vol. 6, no. 1, p. 8129, Dec. 2015. [PubMed: 26350361]

[9]. Rooney P and Kumar S, "Inverse relationship between hyaluronan and collagens in development and angiogenesis.,” Differentiation., vol. 54, no. 1, pp. 1-9, Aug. 1993. [PubMed: 7691668] 
[10]. Ananthanarayanan B, Kim Y, and Kumar S, "Elucidating the mechanobiology of malignant brain tumors using a brain matrixmimetic hyaluronic acid hydrogel platform," Biomaterials , vol. 32, no. 31, pp. 7913-7923, Nov. 2011. [PubMed: 21820737]

[11]. Heldin P and Pertoft H, "Synthesis and Assembly of the Hyaluronan-Containing Coats around Normal Human Mesothelial Cells,” Exp. Cell Res. , vol. 208, no. 2, pp. 422-429, Oct. 1993. [PubMed: 8375471]

[12]. Chanmee T, Ontong P, and Itano N, "Hyaluronan: Cancer and Cancer Metastasis," in Glycoscience: Biology and Medicine , Tokyo: Springer Japan, 2015, pp. 1411-1417.

[13]. Sato N, Kohi S, Hirata K, and Goggins M, "Role of hyaluronan in pancreatic cancer biology and therapy: Once again in the spotlight.," Cancer Sci. , vol. 107, no. 5, pp. 569-75, 52016. [PubMed: 26918382]

[14]. Schwertfeger KL, Cowman MK, Telmer PG, Turley EA, and McCarthy JB, "Hyaluronan, Inflammation, and Breast Cancer Progression.," Front. Immunol , vol. 6, p. 236, 2015. [PubMed: 26106384]

[15]. Chopra A, Murray ME, Byfield FJ, Mendez MG, Halleluyan R, Restle DJ, Raz-Ben Aroush D, Galie PA, Pogoda K, Bucki R, Marcinkiewicz C, Prestwich GD, Zarembinski TI, Chen CS, Puré E, Kresh JY, and Janmey PA, “Augmentation of integrin-mediated mechanotransduction by hyaluronic acid.,” Biomaterials , vol. 35, no. 1, pp. 71-82, Jan. 2014. [PubMed: 24120037]

[16]. Lou J, Stowers R, Nam S, Xia Y, and Chaudhuri O, "Stress relaxing hyaluronic acid-collagen hydrogels promote cell spreading, fiber remodeling, and focal adhesion formation in 3D cell culture," Biomaterials , vol. 154, pp. 213-222, Feb. 2018. [PubMed: 29132046]

[17]. Ievdokimova NI, "[Hyaluronic acid, receptor CD44, and their role in diabetic complications].," Ukr. biokhimichnyi zhurnal (1999), vol. 80, no. 5, pp. 5-44.

[18]. Kouvidi K, Berdiaki A, Nikitovic D, Katonis P, Afratis N, Hascall VC, Karamanos NK, and Tzanakakis GN, "Role of Receptor for Hyaluronic Acid-mediated Motility (RHAMM) in Low Molecular Weight Hyaluronan (LMWHA)-mediated Fibrosarcoma Cell Adhesion,” J. Biol. Chem , vol. 286, no. 44, pp. 38509-38520, Nov. 2011. [PubMed: 21914806]

[19]. Nagaoka A, Yoshida H, Nakamura S, Morikawa T, Kawabata K, Kobayashi M, Sakai S, Takahashi Y, Okada Y, and Inoue S, "Regulation of Hyaluronan (HA) Metabolism Mediated by HYBID (Hyaluronan-binding Protein Involved in HA Depolymerization, KIAA1199) and HA Synthases in Growth Factor-stimulated Fibroblasts.," J. Biol. Chem , vol. 290, no. 52, pp. 3091023, Dec. 2015. [PubMed: 26518873]

[20]. Cunningham CC, Vegners R, Bucki R, Funaki M, Korde N, Hartwig JH, Stossel TP, and Janmey PA, "Cell permeant polyphosphoinositide-binding peptides that block cell motility and actin assembly.," J. Biol. Chem , vol. 276, no. 46, pp. 43390-9, Nov. 2001. [PubMed: 11533030]

[21]. Shibasaki Y, Ishihara H, Kizuki N, Asano T, Oka Y, and Yazaki Y, "Massive actin polymerization induced by phosphatidylinositol-4-phosphate 5-kinase in vivo.," J. Biol. Chem , vol. 272, no. 12, pp. 7578-81, Mar. 1997. [PubMed: 9065410]

[22]. Ramos JR, Pabijan J, Garcia R, and Lekka M, “The softening of human bladder cancer cells happens at an early stage of the malignancy process.," Beilstein J. Nanotechnol , vol. 5, pp. 44757, 2014. [PubMed: 24778971]

[23]. Janke M, Herrig A, Austermann J, Gerke V, Steinem C, and Janshoff A, "Actin Binding of Ezrin Is Activated by Specific Recognition of PIP 2 -Functionalized Lipid Bilayers $\dagger$," Biochemistry , vol. 47, no. 12, pp. 3762-3769, Mar. 2008. [PubMed: 18302339]

[24]. Sakisaka T, Itoh T, Miura K, and Takenawa T, "Phosphatidylinositol 4,5-bisphosphate phosphatase regulates the rearrangement of actin filaments.," Mol. Cell. Biol, vol. 17, no. 7, pp. 3841-9, Jul. 1997. [PubMed: 9199318]

[25]. Park WS, Do Heo W, Whalen JH, O’Rourke NA, Bryan HM, Meyer T, and Teruel MN, "Comprehensive identification of PIP3-regulated PH domains from C. elegans to H. sapiens by model prediction and live imaging.," Mol. Cell , vol. 30, no. 3, pp. 381-92, 5 2008. [PubMed: 18471983]

[26]. Raucher D and Sheetz MP, "Cell Spreading and Lamellipodial Extension Rate Is Regulated by Membrane Tension,” J. Cell Biol. , vol. 148, no. 1, pp. 127-136, 2000. [PubMed: 10629223] 
[27]. Sheetz MP, “Cell control by membrane-cytoskeleton adhesion,” Nat. Rev. Mol. Cell Biol , vol. 2, no. 5, pp. 392-396, 5 2001. [PubMed: 11331914]

[28]. Stefani C, Gonzalez-Rodriguez D, Senju Y, Doye A, Efimova N, Janel S, Lipuma J, Tsai MC, Hamaoui D, Maddugoda MP, Cochet-Escartin O, Prévost C, Lafont F, Svitkina T, Lappalainen P, Bassereau P, and Lemichez E, "Ezrin enhances line tension along transcellular tunnel edges via NMIIa driven actomyosin cable formation," Nat. Commun , vol. 8, p. 15839, Jun. 2017. [PubMed: 28643776]

[29]. Reversi A, Loeser E, Subramanian D, Schultz C, and De Renzis S, "Plasma membrane phosphoinositide balance regulates cell shape during Drosophila embryo morphogenesis," J. Cell Biol. , vol. 205, no. 3, pp. 395-408, 5 2014. [PubMed: 24798734]

[30]. Mandal K, Wang I, Vitiello E, Orellana LAC, and Balland M, "Cell dipole behaviour revealed by ECM sub-cellular geometry.,” Nat. Commun , vol. 5, p. 5749, 2014. [PubMed: 25494455]

[31]. Nakabayashi H, Taketa K, Miyano K, Yamane T, and Sato J, "Growth of human hepatoma cells lines with differentiated functions in chemically defined medium.," Cancer Res. , vol. 42, no. 9, pp. 3858-63, Sep. 1982. [PubMed: 6286115]

[32]. Guet D, Mandal K, Pinot M, Hoffmann J, Abidine Y, Sigaut W, Bardin S, Schauer K, Goud B, and Manneville JB, "Mechanical role of actin dynamics in the rheology of the Golgi complex and in Golgi-associated trafficking events," Curr. Biol , vol. 24, no. 15, pp. 1700-1711, 2014. [PubMed: 25042587]

[33]. Butler JP, Tolic-Norrelykke IM, Fabry B, and Fredberg JJ, "Traction fields, moments, and strain energy that cells exert on their surroundings,” AJP Cell Physiol. , vol. 282, no. 3, pp. C595C605, 2002.

[34]. Tolic-Norrelykke IM, Butler JP, Chen J, and Wang N, "Spatial and temporal traction response in human airway smooth muscle cells," AJP Cell Physiol. , vol. 283, no. 4, pp. C1254-C1266, 2002.

[35]. Moore DT, Nygren P, Jo H, Boesze-Battaglia K, Bennett JS, and DeGrado WF, “Affinity of talin-1 for the $\beta 3$-integrin cytosolic domain is modulated by its phospholipid bilayer environment.," Proc. Natl. Acad. Sci. U. S. A , vol. 109, no. 3, pp. 793-8, Jan. 2012. [PubMed: 22210111]

[36]. Mcnamee HP, Liley HG, and Ingber DE, "Integrin-Dependent Control of Inositol Lipid Synthesis in Vascular Endothelial Cells and Smooth Muscle Cells," Exp. Cell Res. , vol. 224, pp. 116-122, 1996. [PubMed: 8612675]

[37]. Legate KR, Takahashi S, Bonakdar N, Fabry B, Boettiger D, Zent R, and Fässler R, "Integrin adhesion and force coupling are independently regulated by localized PtdIns(4,5)2 synthesis.," EMBO J. , vol. 30, no. 22, pp. 4539-53, Nov. 2011. [PubMed: 21926969]

[38]. Guillou H, Lécureuil C, Anderson KE, Suire S, Ferguson GJ, Ellson CD, Gray A, Divecha N, Hawkins PT, and Stephens LR, "Use of the GRP1 PH domain as a tool to measure the relative levels of PtdIns(3,4,5)P3 through a protein-lipid overlay approach.," J. Lipid Res. , vol. 48, no. 3, pp. 726-32, Mar. 2007. [PubMed: 17130283]

[39]. Vasudevan KM, Barbie DA, Davies MA, Rabinovsky R, McNear CJ, Kim JJ, Hennessy BT, Tseng H, Pochanard P, Kim SY, Dunn IF, Schinzel AC, Sandy P, Hoersch S, Sheng Q, Gupta PB, Boehm JS, Reiling JH, Silver S, Lu Y, Stemke-Hale K, Dutta B, Joy C, Sahin AA, GonzalezAngulo AM, Lluch A, Rameh LE, Jacks T, Root DE, Lander ES, Mills GB, Hahn WC, Sellers WR, and Garraway LA, "AKT-independent signaling downstream of oncogenic PIK3CA mutations in human cancer.," Cancer Cell , vol. 16, no. 1, pp. 21-32, Jul. 2009. [PubMed: 19573809]

[40]. Masters TA, Pontes B, Viasnoff V, Li Y, Gauthier NC, and Vale RD, "Plasma membrane tension orchestrates membrane trafficking, cytoskeletal remodeling, and biochemical signaling during phagocytosis."

[41]. Hall CL, Yang B, Yang X, Zhang S, Turley M, Samuel S, Lange LA, Wang C, Curpen GD, Savani RC, Greenberg AH, and Turley EA, "Overexpression of the hyaluronan receptor RHAMM is transforming and is also required for H-ras transformation.," Cell , vol. 82, no. 1, pp. 19-26, Jul. 1995. [PubMed: 7541721] 
[42]. Yeung T, Georges PC, Flanagan LA, Marg B, Ortiz M, Funaki M, Zahir N, Ming W, Weaver V, and Janmey PA, "Effects of substrate stiffness on cell morphology, cytoskeletal structure, and adhesion," Cell Motil. Cytoskeleton , vol. 60, no. 1, pp. 24-34, Jan. 2005. [PubMed: 15573414]

[43]. Yin HL and Janmey PA, "Phosphoinositide Regulation of the Actin Cytoskeleton," Annu. Rev. Physiol , vol. 65, no. 1, pp. 761-789, Mar. 2003. [PubMed: 12471164]

[44]. Mandal K, Asnacios A, Goud B, and Manneville J-B, "Mapping intracellular mechanics on micropatterned substrates,” Proc. Natl. Acad. Sci , vol. 113, no. 46, pp. E7159-E7168, 2016. [PubMed: 27799529]

[45]. Burdick JA and Prestwich GD, "Hyaluronic Acid Hydrogels for Biomedical Applications," Adv. Mater, vol. 23, no. 12, pp. H41-H56, Mar. 2011. [PubMed: 21394792]

[46]. Ramakrishnan N, Sreeja KK, Roychoudhury A, Eckmann DM, Ayyaswamy PS, Baumgart T, Pucadyil T, Patil S, Weaver VM, and Radhakrishnan R, "Excess area dependent scaling behavior of nano-sized membrane tethers," Phys. Biol , vol. 15, no. 2, p. 026002, Jan. 2018. [PubMed: 29116056]

[47]. Zhang X, Orlando K, He B, Xi F, Zhang J, Zajac A, and Guo W, "Membrane association and functional regulation of Sec3 by phospholipids and Cdc42.," J. Cell Biol. , vol. 180, no. 1, pp. 145-58, Jan. 2008. [PubMed: 18195105]

[48]. Heinrich M, Tian A, Esposito C, and Baumgart T, "Dynamic sorting of lipids and proteins in membrane tubes with a moving phase boundary.," Proc. Natl. Acad. Sci. U. S. A, vol. 107, no. 16, pp. 7208-13, Apr. 2010. [PubMed: 20368457]

[49]. Mattila PK, Pykäläinen A, Saarikangas J, Paavilainen VO, Vihinen H, Jokitalo E, and Lappalainen P, "Missing-in-metastasis and IRSp53 deform PI(4,5)P2-rich membranes by an inverse BAR domain-like mechanism," J. Cell Biol. , 2007.

[50]. Winer JP, Janmey PA, McCormick ME, and Funaki M, "Bone Marrow-Derived Human Mesenchymal Stem Cells Become Quiescent on Soft Substrates but Remain Responsive to Chemical or Mechanical Stimuli," Tissue Eng. Part A, vol. 15, no. 1, pp. 147-154, Jan. 2009. [PubMed: 18673086]

[51]. Lu Y-B, Franze K, Seifert G, Steinhäuser C, Kirchhoff F, Wolburg H, Guck J, Janmey P, Wei EQ, Käs J, and Reichenbach A, "Viscoelastic properties of individual glial cells and neurons in the CNS.,” Proc. Natl. Acad. Sci. U. S. A, vol. 103, no. 47, pp. 17759-64, Nov. 2006. [PubMed: 17093050]

[52]. Ghibaudo M, Saez A, Trichet L, Xayaphoummine A, Browaeys J, Silberzan P, Buguin A, and Ladoux B, "Traction forces and rigidity sensing regulate cell functions," Soft Matter, vol. 4, no. 9, p. 1836, Aug. 2008.

[53]. Wyss HM, Henderson JM, Byfield FJ, Bruggeman LA, Ding Y, Huang C, Suh JH, Franke T, Mele E, Pollak MR, Miner JH, Janmey PA, Weitz DA, and Miller RT, "Biophysical properties of normal and diseased renal glomeruli," Am. J. Physiol. Physiol, vol. 300, no. 3, pp. C397-C405, Mar. 2011.

[54]. Barnhart EL, Lee K-C, Keren K, Mogilner A, and Theriot JA, “An dhesion-Dependent Switch between Mechanisms That Determine Motile Cell Shape,” PLoS Biol., vol. 9, no. 5, p. e1001059, 5 2011. [PubMed: 21559321]

[55]. Pogoda K, Bucki R, Byfield FJ, Cruz K, Lee T, Marcinkiewicz C, and Janmey PA, "Soft Substrates Containing Hyaluronan Mimic the Effects of Increased Stiffness on Morphology, Motility, and Proliferation of Glioma Cells," Biomacromolecules , vol. 18, no. 10, pp. 30403051, Oct. 2017. [PubMed: 28858529]

[56]. Rouven Brückner B, Pietuch A, Nehls S, Rother J, and Janshoff A, "Ezrin is a Major Regulator of Membrane Tension in Epithelial Cells.," Sci. Rep , vol. 5, p. 14700, Oct. 2015. [PubMed: 26435322]

[57]. Janmey PA, Bucki R, Radhakrishnan R (2018) Regulation of actin assembly by PI(4,5)P2 and other inositol phospholipids: an update on possible mechanisms. Biochemical and Biophysical Research Communications. (In press) 

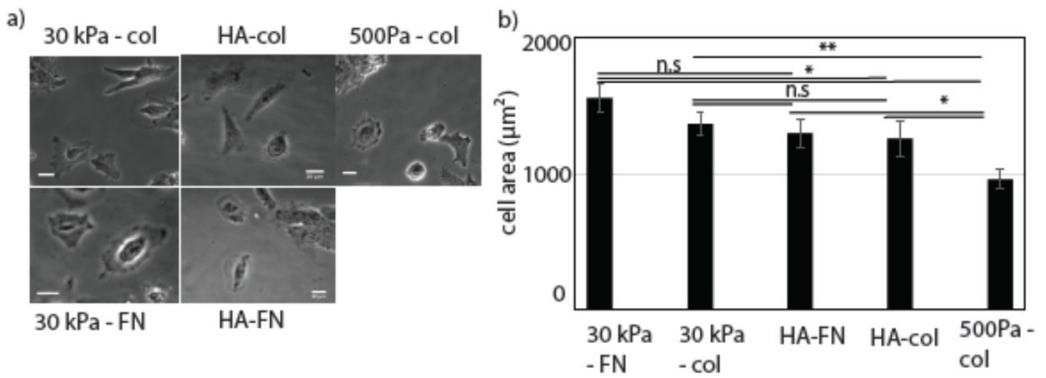

b)

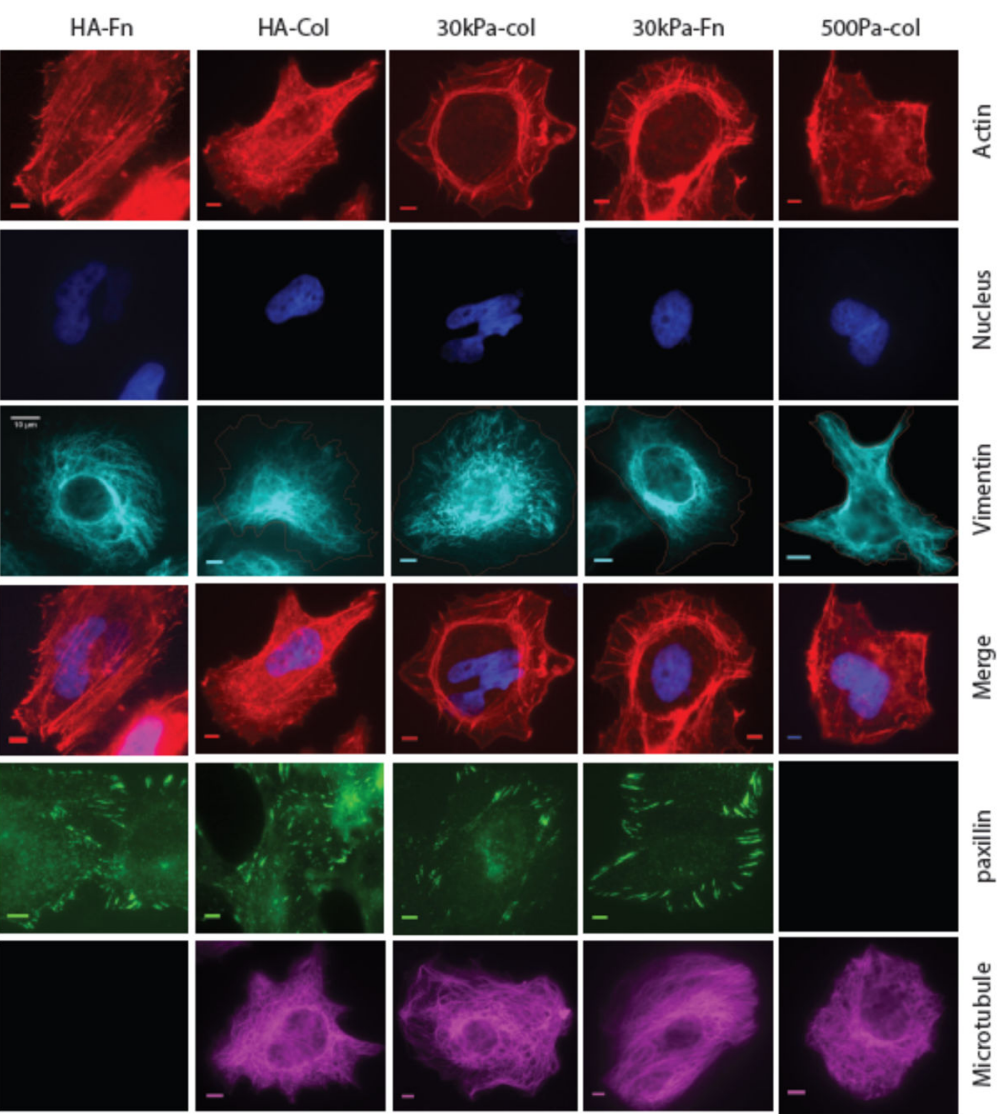

Figure1: Cell Spreading on HA and PAA substrate.

Huh7 cell spreading on different substrate with varying stiffness and ligand binding (Collagen (Col) and Fibronectin (FN)). Cells are grown on HA and 30kPa substrates for 24 hrs (a) bright field image of the cells on HA-FN, HA-col, 30kPa-Col, 30kPa-FN, $500 \mathrm{~Pa}$ Col substrates are shown. (Scale bar, $20 \mu \mathrm{m}$ ). (right). (b) Huh7 cell area quantified on HA and PAA gel. Error bars represent standard error mean of N30kPa-col $=34, \mathrm{~N} 30 \mathrm{kPa}-\mathrm{FN}=29$ and $\mathrm{N}_{\text {HA-FN }}=25, \mathrm{~N}_{\text {HA-col }}=36, \mathrm{~N} 500 \mathrm{~Pa}$-col $=26$ ) cells on these substrates respectively. $\mathrm{p}$-values are determined from Student's t-test for unpaired samples $\mathrm{f}(* * \mathrm{p}<0.005 ; * \mathrm{p}<0.05$, n.a $\mathrm{p}>$ 0.05). (c) Formation of stress fibers, cytoskeleton organization and FAs on HA and $30 \mathrm{kPa}$ substrates. Actin (red), Nucleus (blue), Vimentin (cyan) merge(right), (Scale bar, $5 \mu \mathrm{m}$ ). 
a)
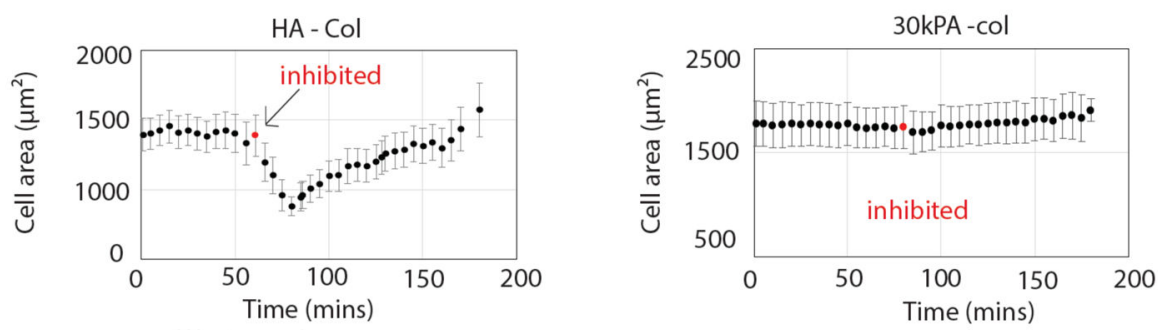

b)
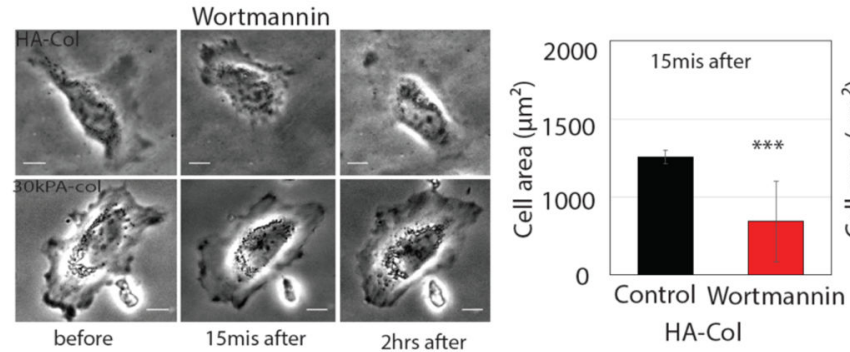

$\mathrm{HA}-\mathrm{Col}$

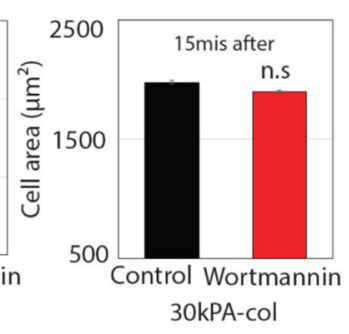

c)
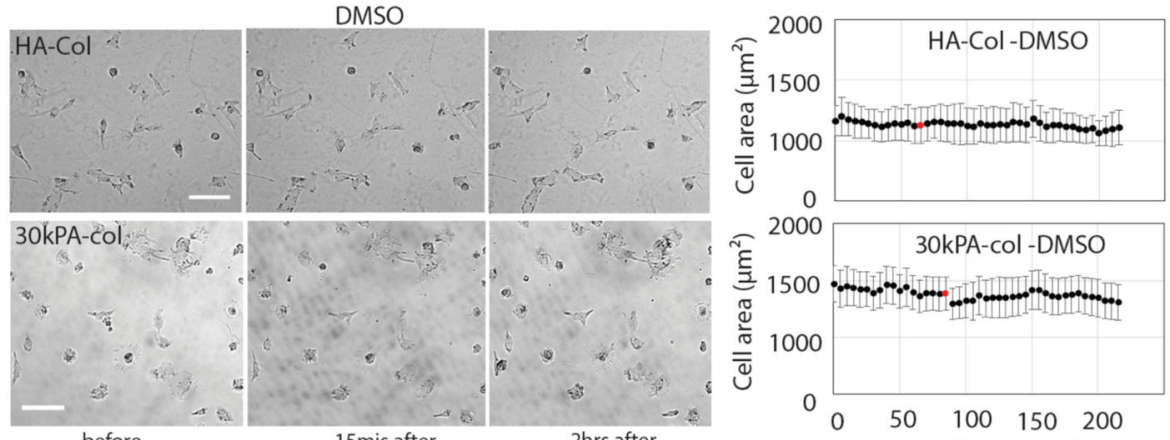

d)
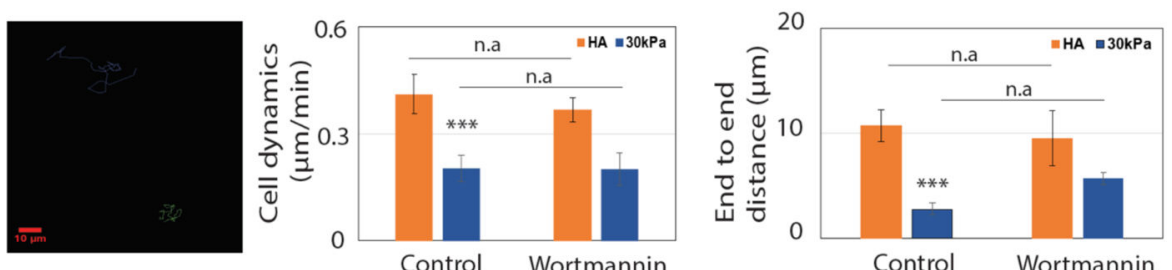

Figure2: Effect of PI3K inhibition in Huh7 cells by wortmannin

Inhibition of PI3K in Huh7 cells grown on HA and $30 \mathrm{kPa}$. (a) Average cell area change is observed during $3 \mathrm{hrs}$ of time period on both HA-col (left) and $30 \mathrm{kPa}-\mathrm{col}$ (right). PI3K is inhibited by wortmannin after $1 \mathrm{~h}$ (red) of control imaging. ( $\mathrm{N}=16$ and 23 cells on HA and 30 $\mathrm{kPa}$ respectively). (b) (left) Bright field image of the cells before, $15 \mathrm{mins}$ after and $2 \mathrm{hrs}$ after of adding wortmannin (Scale bar, $10 \mu \mathrm{m}$ ). (right) Cell area after 15 mins of wortmannin treatment are calculated. (c) (left) Bright field image of the cells before, 15mins after and 2 hrs after of adding DMSO (Scale bar, $100 \mu \mathrm{m}$ ). (right) Average cell area change over $3 \mathrm{hrs}$ time period shown in the figure ( $\mathrm{N}=11$ and 15 cells on HA and $30 \mathrm{kPa}$ respectively). (d) (left) Cell dynamics have been shown by tracking the centroid of the cell on HA and $30 \mathrm{kPa}$ substrates for both control and drug conditions. End to end distance are calculated by using initial and final centroid position of the cell. $(\mathrm{N}=16$ and 23 cells on $\mathrm{HA}$ and $30 \mathrm{kPa}$ respectively). All error bars represent standard error mean. $\mathrm{P}$ values are determined from 
Student's t test for unpaired samples with respect to control cells $(* * * \mathrm{P}<0.0001$; **P $<$ 0.001 ; and $* \mathrm{P}<0.01)$. 

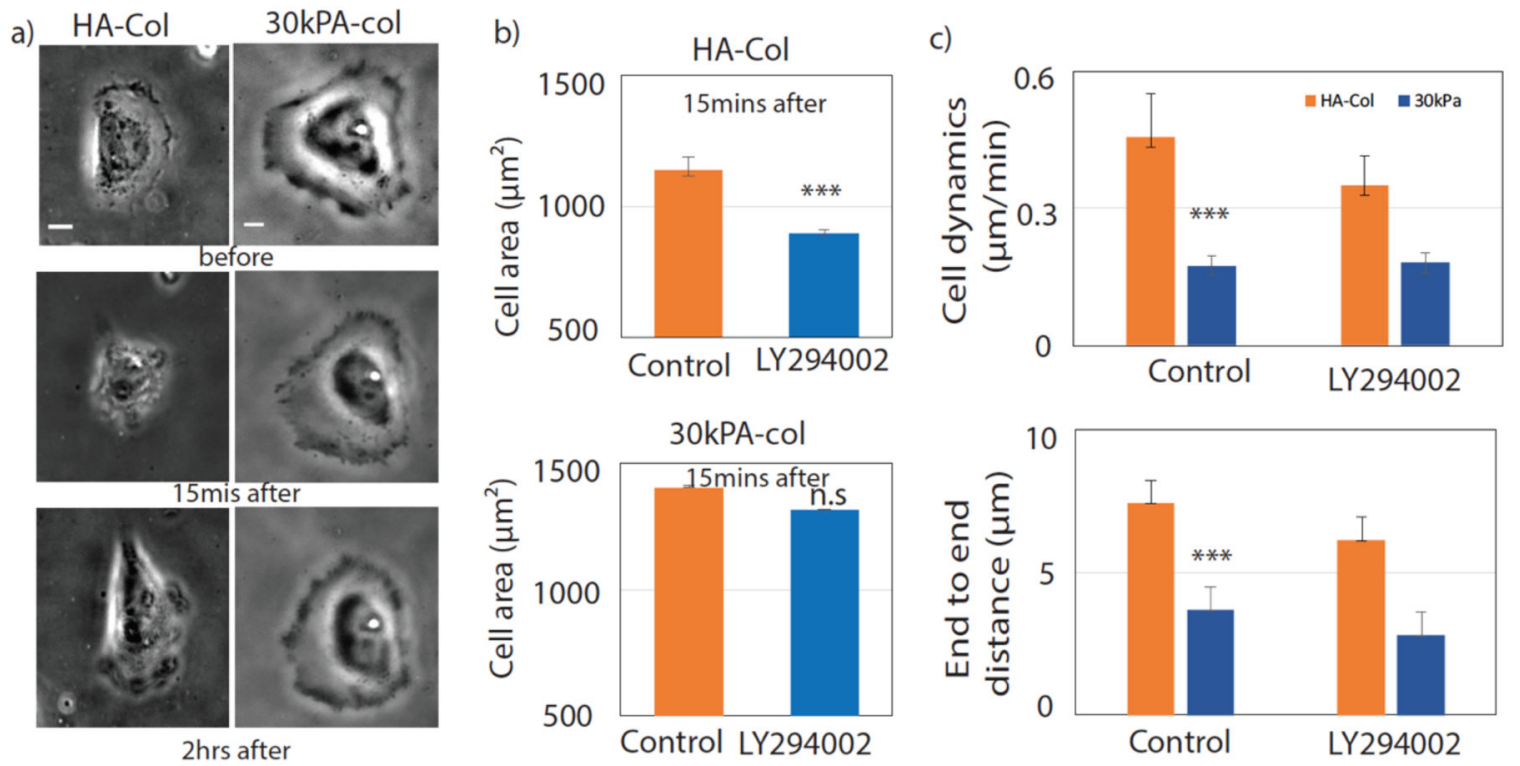

Figure3: Inhibition of PI3K by LY296004

Inhibition of PI3K by LY296004 in Huh7 cells grown on HA and $30 \mathrm{kPa}$. PI3K is inhibited by LY296004 after 1h (red) of control imaging. (a) Bright field image of the cells before, 15mins after and $2 \mathrm{hrs}$ after of adding LY296004 (Scale bar, $10 \mu \mathrm{m}$ ). (b) Cell area before adding the drug and after 15 mins of LY296004 treatment are calculated on HA (N=21) and $30 \mathrm{kPa}$ (11 cells) respectively. (c) Cell dynamics have been shown by tracking the centroid of the cell on HA and $30 \mathrm{kPa}$ substrates (Scale bar, $10 \mu \mathrm{m}$ ). Average cell dynamics for both control and drug conditions are calculaed. End to end distance are calculated by using initial and final centroid position of the cell. All error bars represent standard error mean. $\mathrm{P}$ values are determined from Student's $\mathrm{t}$ test for unpaired samples with respect to control cells (***P $<0.0001 ; * * \mathrm{P}<0.001$; and $* \mathrm{P}<0.01)$. 
a)

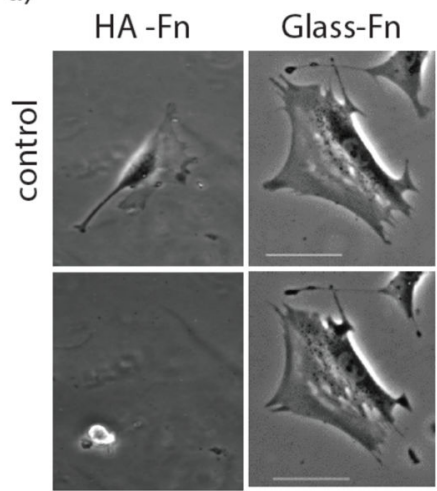

PBP10

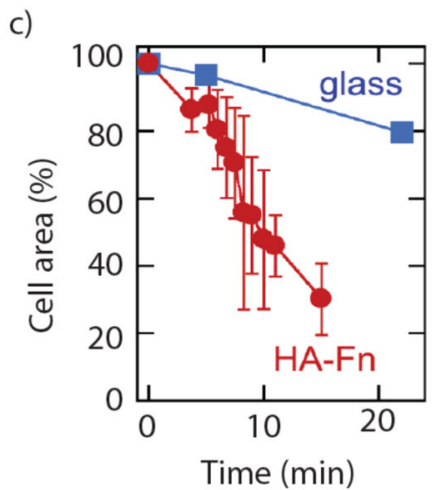

$\mathrm{HA}-\mathrm{Fn}$

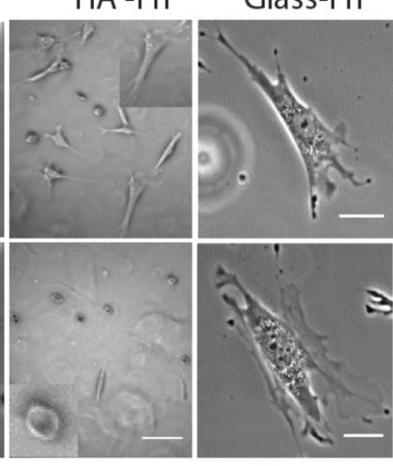

wortmannin
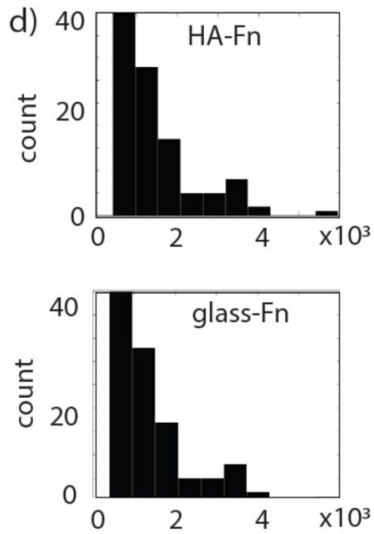

b)
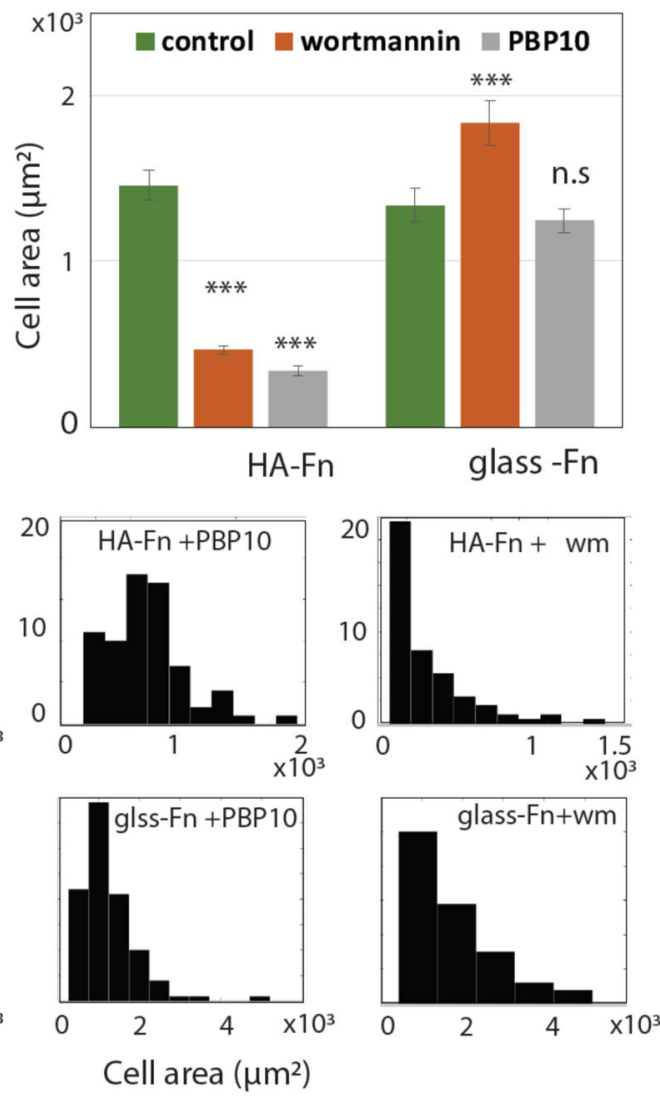

Figure 4: Effect of PbP10 and wortmannin inhibition on $3 T 3$ fibroblasts Inhibition of PIP2 by PBP10 and PIP3 by wortmannin in 3T3 fibroblast cells grown on HAFn and glass-Fn and $300 \mathrm{~Pa}$-PAA gel. (a) Bright field image of the cells before and 22 mins after adding PBP10 or wortmannin (Scale bar, HA-50 and $10 \mu \mathrm{m}$; glass 50 and $10 \mu \mathrm{m}$ ). (b) Area calculated before and after adding the drug treatment HA-Fn $\left(\mathrm{N}_{\mathrm{ctl}}=113, \mathrm{NPBP} 10=119\right.$ and $\left.\mathrm{N}_{\mathrm{wm}}=84\right)$ and glass-Fn $\left(\mathrm{N}_{\mathrm{ctl}}=67, \mathrm{NPBP} 10=102\right.$ and $\left.\mathrm{N}_{\mathrm{wm}}=96\right)$ respectively. (c) percentage change area on glass and HA over time are shown. Area histograms shown for HA and glass substrates when cells are treated with/without PBP10 and wortmannin. All error bars represent standard error mean. $\mathrm{P}$ values are determined from Student's $\mathrm{t}$ test for unpaired samples with respect to control cells (***P $<0.0001$; **P $<0.001$; and $* \mathrm{P}<0.01$ ). 
a)

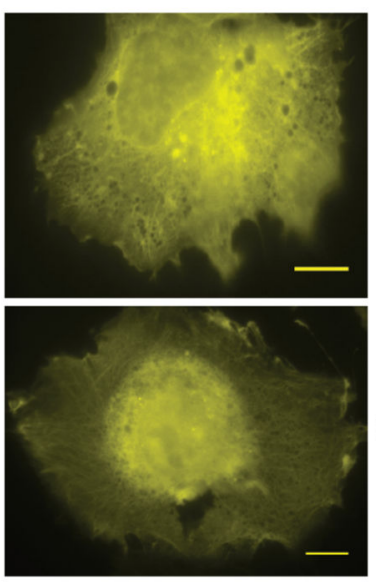

PIP3
$\mathrm{HA}$

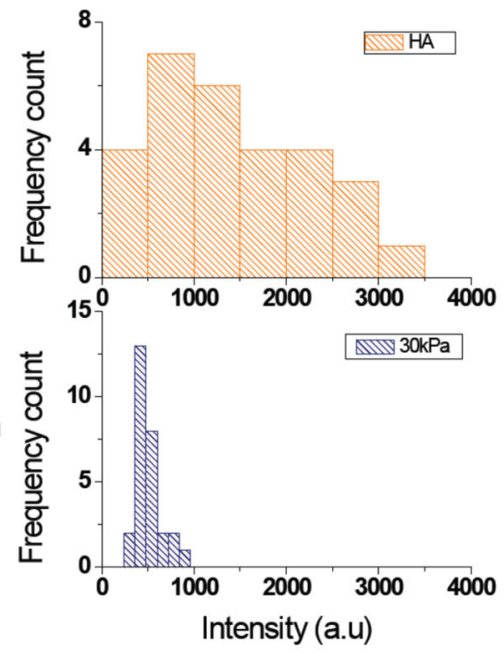

b) $\times 1000$

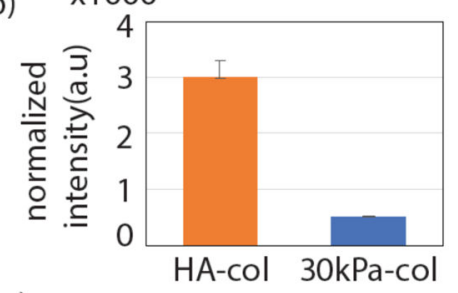

c)

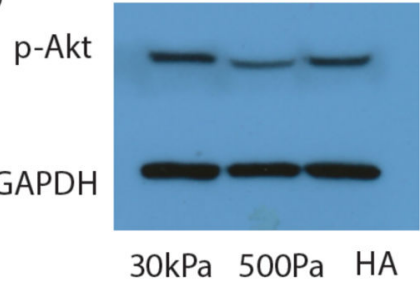

Figure5. PIP3 quantification and Akt expression by western blot

PIP3 and Akt expression level on HA and $30 \mathrm{kPa}$ substrates. Huh7 Cells are grown on these two substrate for $24 \mathrm{hrs}$. m-cherry-Grp1 images (Yellow) are shown (Scale bar, $10 \mu \mathrm{m}$ ). Intensities are normalized by individual cell area and intensity histograms are plotted. (b) Average normalized intensities are plotted $(\mathrm{N}=29$ and 28 cells on $\mathrm{HA}$ and $30 \mathrm{kPa}$ respectively). (c) Huh7 cells growing on HA and 30kPa gels were lysed 24hrs after plating and processed for immunoblot. 
a)
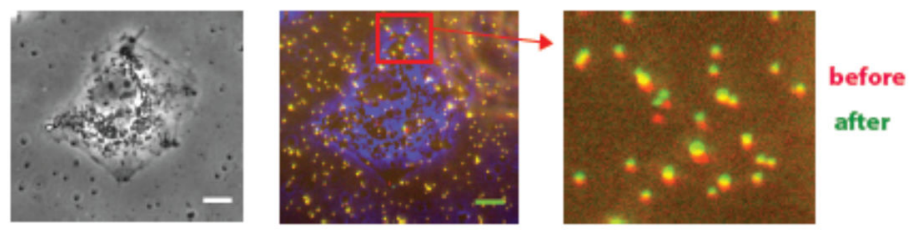

b)

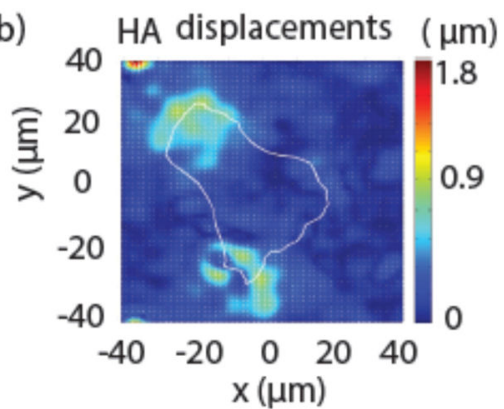

d)

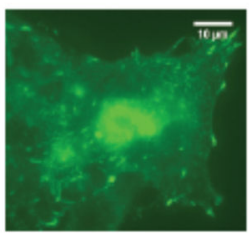

$\mathrm{HA}$

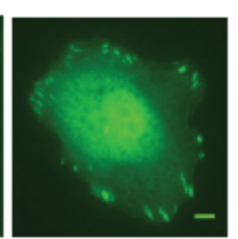

$30 \mathrm{kPa}$

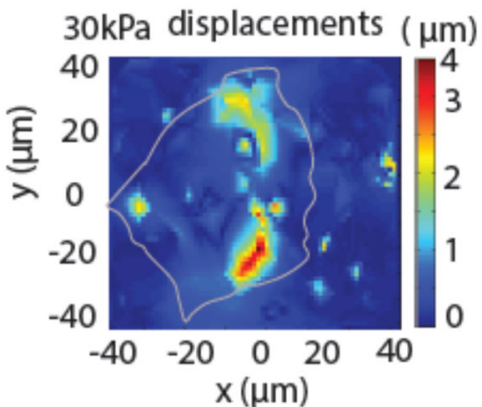

e)

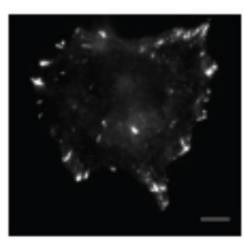

c)
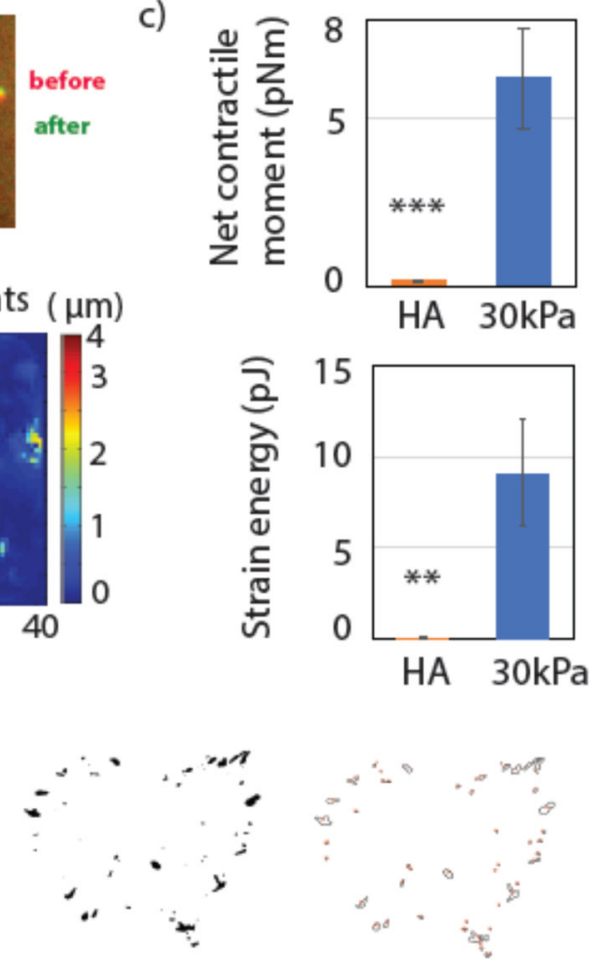

f)
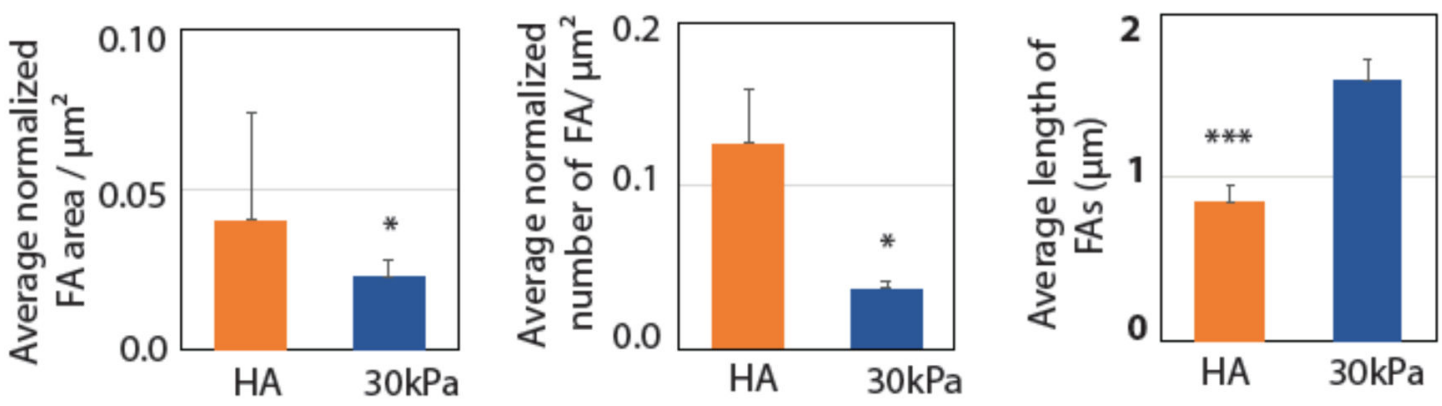

Figure 6: Cell traction force and adhesion

Cell substrate interaction is determined by traction force measurement and focal adhesion. Huh7 cells are grown on HA and $30 \mathrm{kPa}$ substrates for $24 \mathrm{hrs}$. (a) (left) Bright field image of the cell; (middle) marge image of cell (blue), stressed beads(red) and relaxed beads(green); (right) bead displacement towards the center of the cell. (Scale bar, $10 \mu \mathrm{m}$ ). (b) Bead displacement fields are shown for the cells on HA and $30 \mathrm{kPa}$. (c) Average net contractile moment and strain energy are shown. ( $N=7$ and 11 cells respectively for HA and $30 \mathrm{kPa}$ substrates). (d) Immunostaining images of Paxillin (green) are shown. Intensity thresholded image and Focal adhesion boundaries are shown (Scale bar, $10 \mu \mathrm{m}$ ). (e) Average Focal adhesion area, average number of FAs ( $N=15$ and 16 cells on HA and $30 \mathrm{kPa}$ respectively) and FA length are plotted on HA and 30kPa substrate. All the FA areas and lengths are normalized by the individual cell area. Error bars are standard error mean. p-values are determined from Student's t-test for unpaired samples $\mathrm{f}(* * \mathrm{p}<0.005 ; * \mathrm{p}<0.05)$. 
a)

b)
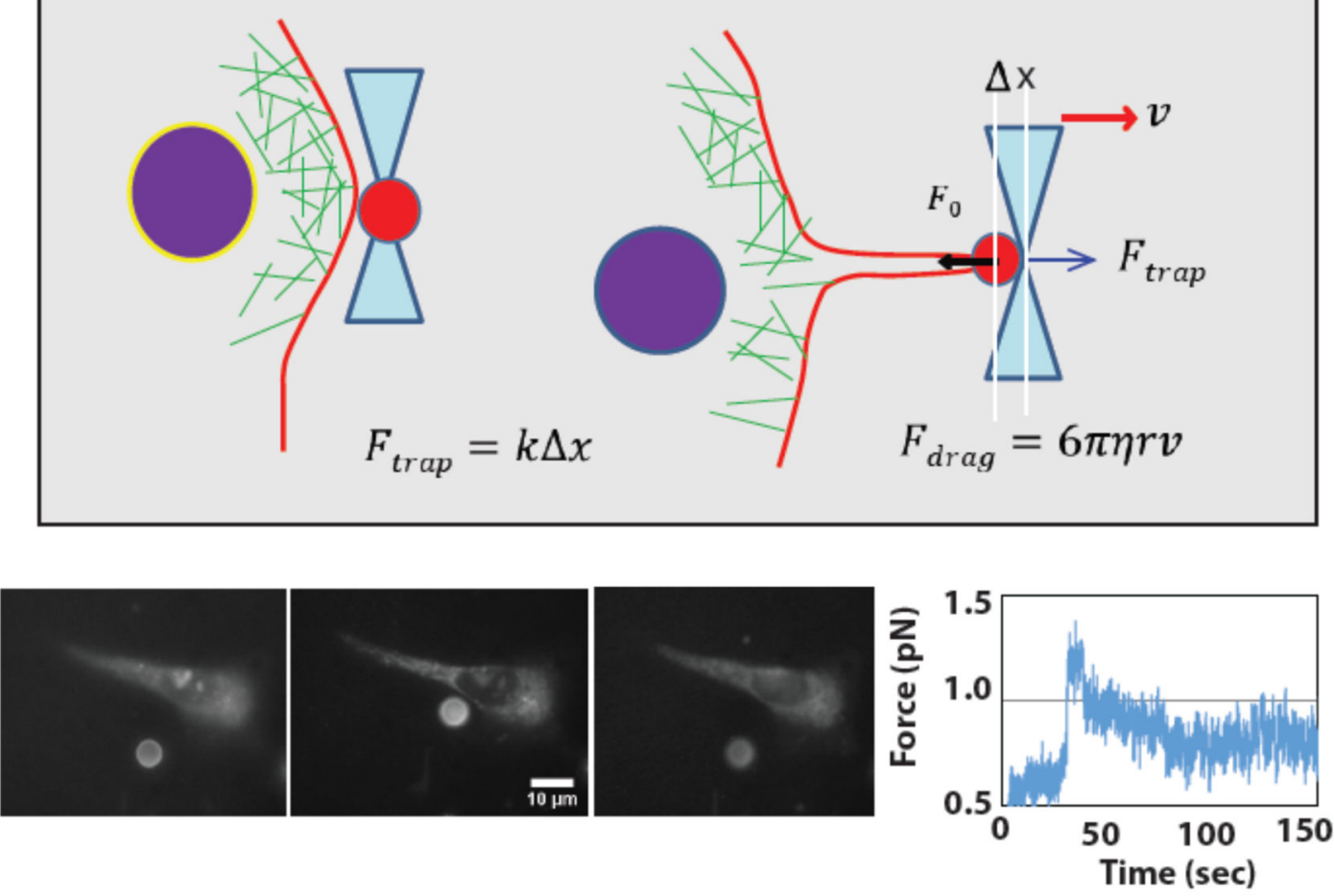

c)
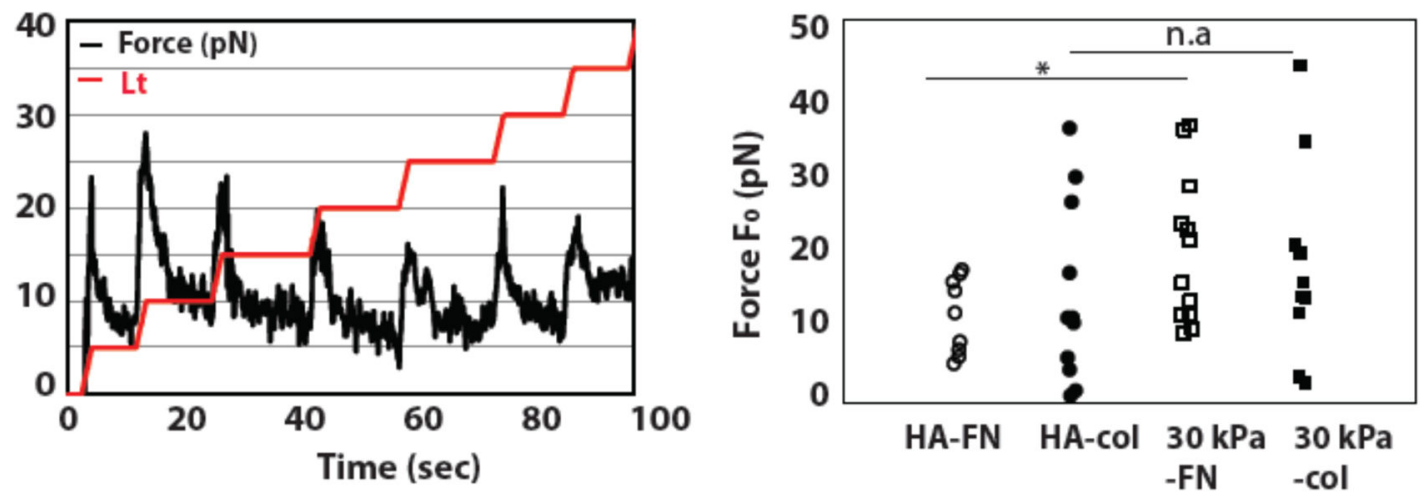

Figure 7: Huh7 cell membrane Tension measured by optical tweezers

Tether pulling experiment by Optical tweezers to measure Huh7 cell membrane tension. (a)Schematic of the tether pulling experiment. The bead is initially trapped at the center of the optical tweezers. The bead is taken near to membrane and left for 30 s for interaction. Tether is pulled by displacing the bead away from the cell. (b) (left) Fluorescent image of the bead and cell before and after pulling tether. (right) A single force curve over time shown for single displacement. (c) (left) Tether is pulled by displacing the bead in a stepwise fashion away from the cell. $0.5 \mu \mathrm{m}$ distance in HA-Fn $(\mathrm{N}=9)$, HA-col $(\mathrm{N}=11), 30 \mathrm{kPa}-$ $\mathrm{Fn}(\mathrm{N}=12), 30 \mathrm{kPa}-\mathrm{col}(\mathrm{N}=10)$ are measured. p-values are determined from Student's t-test for unpaired samples $f(* * p<0.005 ; * p<0.05)$. 